\title{
Christine de Pizan. Una città per sé. A cura di Patrizia Caraffi
}

\section{Giorgia Puttero}

\section{Q OpenEdition}

1 Journals

\section{Edizione digitale}

URL: https://journals.openedition.org/studifrancesi/39007

DOI: $10.4000 /$ studifrancesi.39007

ISSN: 2421-5856

\section{Editore}

Rosenberg \& Sellier

\section{Edizione cartacea}

Data di pubblicazione: 1 décembre 2004

Paginazione: 339-340

ISSN: 0039-2944

\section{Notizia bibliografica digitale}

Giorgia Puttero, «Christine de Pizan. Una città per sé. A cura di Patrizia Caraffi», Studi Francesi [Online],

143 (XLVIII | II) | 2004, online dal 30 novembre 2015, consultato il 19 mai 2021. URL: http://

journals.openedition.org/studifrancesi/39007 ; DOI: https://doi.org/10.4000/studifrancesi.39007

Questo documento è stato generato automaticamente il 19 mai 2021.

\section{(c) $(1) \odot \odot$}

Studi Francesi è distribuita con Licenza Creative Commons Attribuzione - Non commerciale - Non opere derivate 4.0 Internazionale. 


\title{
Christine de Pizan. Una città per sé. A cura di Patrizia Caraffi
}

\author{
Giorgia Puttero
}

\section{NOTIZIA}

Christine de Pizan. Una città per sé. A cura di Patrizia CARAFFI, Roma, Carocci Editore, 2003 («Biblioteca Medievale. Saggi/10»), pp. 118.

1 Nel tentativo arduo di proporre spunti di lettura ancora inediti, il saggio affronta aspetti della scrittura e della personalità di Christine de Pizan con il «desiderio che la voce autorevole di questa grande autrice sia finalmente ascoltata e capita in tutta la sua grandezza» (p. 11 dell'introduzione). Sette sono i contributi raccolti. Il primo, che viene comunque dopo un'accurata cronologia delle opere della Pizan ed un utile aggiornamento bibliografico, porta la firma di PATRIZIA CARAFFI ed è intitolato Il Libro e la Città: metafore architettoniche e costruzione di una genealogia femminile (pp. 19-31). In esso, l'A. ritrova nella scrittura il vero atto fondatore di quel nuovo regno delle Donne immaginato nella Cité des Dames, di quella Città che è vista soprattutto come luogo di difesa dalla violenza fisica e verbale. Un tema, quello della violenza sulle donne, che la Caraffi riconosce di sorprendente attualità.

2 MARGARETE ZIMMERMANN (La scrittrice della memoria, pp. 33-45) s'interroga invece sul perché di due manchevolezze notate ai nostri giorni. La prima è la marginalità di cui soffre l'autrice medievale nel suo paese d'origine, l'Italia; la seconda è l'assenza di riferimenti alla stessa nei dibattiti politici che attualmente in Europa interessano la memoria, in quanto fenomeno socioculturale, sebbene l'opera della Pizan offra un'ampia gamma di modi di pensare e di praticare la memoria.

3 Il terzo saggio. All'origine della rappresentazione della lettrice e della scrittrice: Christine de Pizan di TIZIANA PLEBANI (pp. 47-58), è volto ad attribuire a Christine il ruolo che le spetta sia all'interno della storia del libro, nel mondo della produzione e circolazione dei testi nel tardo Medioevo, sia nella costruzione e nella tradizione dell'iconografia 
dell'intellettuale. Nel contributo di GIOVANNA ANGELI, Christine de Pizan o il tramonto del cuore virile (pp. 59-69), il tramonto di cui si scrive accade in virtù della considerazione che «se le donne [presentate dalla Pizan] sono coraggiose, dotte, intelligenti, astute, fedeli, non è perché cercano di assomigliare agli uomini ma perché sono donne» (p. 66); un convincimento che genera una concezione delle virtù e dei vizi alfine asessuata.

4 JACQUeline Cerquiglini-TOUlet, Christine de Pizan: dalla conocchia alla penna (pp. 71-85), osserva invece il ribaltamento operato dalla Pizan del luogo comune che voleva le donne capaci solo di piangere e di filare: nella progressiva conquista della scrittura attuata dalle donne a fine medioevo, Christine promuove infatti una scrittura femminile dapprima solo lirica e pedagogica, e poi anche scientifica.

5 La «Querelle des femmes» nella «Città delle Dame» di MARIA MILAGROS RIVERA GARRETAS (pp. 87-97) si occupa di quella disputa di ordine simbolico e politico che fu la Querelle des femmes (che l'autrice collega pure alla Frauenfrage) e di come la Pizan, insieme ad altre, sia intervenuta nel dibattito promuovendo la teoria dell'uguaglianza o unità dei sessi. L'intervento di EARL JEFFREY RICHARDS, Sulla natura delle donne e la scrittura di genere (pp. 99-115) chiude questa raccolta di saggi affrontando l'essenzialismo medievale e l'opera di opposizione della Pizan a questo pensiero. 